\title{
The Role of Freedom in the Practical Philosophy of Kant and Reinhold
}

\author{
By Ivanilde Fracalossi
}

\begin{abstract}
It is a question of ascertaining, at first, the difficulties that prevented Reinhold from carrying out the long-sought deduction of a free and absolute cause for freedom of will within the framework of elementary philosophy, or in the plan of the faculty of representation in general. In a second moment, I briefly analyze the author's new strategy when trying to carrying out, or at least to deepen, his foundational approach through practical philosophy. These two movements have Kantian philosophy as a background. In fact, Reinhold takes this starting point after analyzing Kant's work and considering it problematic in some points, mainly the foundation of the effectiveness of freedom in the fact of reason.
\end{abstract}

Keywords: Reinhold, Kant, freedom, representation, foundation

\section{Introduction}

This paper brings as its central issue the problem of the relationship between the unique foundation of philosophy, sought by Karl Leonhard Reinhold (17571823) throughout his philosophical journey, and the deduction of a free and absolute cause for the freedom of the will, remembering that he also prioritizes practical philosophy in relation to the theoretical. I will highlight, first, the difficulties that prevented him from realizing the deduction of the moral law based on the faculty of representation in general, laboriously worked mainly on the 1789 text entitled: Essay on a new theory of the human faculty of representation ${ }^{1}$. Secondly, I verify how these difficulties are evidenced, above all, by Carl Schmid's ${ }^{2}$ objections to his project. Schmid's criticism is important, because it is from there that Reinhold gives new impetus to his philosophy ${ }^{3}$. And, finally, I try to assess the changes that Reinhold, in response to Schmid, imprints on his philosophy from the texts of 1792, especially in second edition of the Letters on Kantian philosophy, where he does not seek longer to prove the non-impossibility of freedom departing from the faculty of representation in general, but he proposes the concept of freedom of the will (Freiheit des Willens) as the foundation of the moral law, based on the relationship between sane understanding and philosophical reason. The general hypothesis of this investigation is that in this entire journey, Reinhold, far from abandoning the old project of a fundamental doctrine of

\footnotetext{
*Post-Doctoral Researcher, Federal University of São Carlos (UFSCar) with Scholarship of Research Support Foundation of the State of São Paulo (FAPESP), Brazil.

${ }^{1}$ Versuch einer neuen Theorie des menschlichen Vorstellungsvermögens. Henceforth, Essay.

${ }^{2}$ Empirical psychology (Empirische Psychologie).

${ }^{3}$ Reinhold's letter to Baggesen of March 28, 1792 shows the conceptual change in his philosophical journey and the departure from Kantian philosophy.
} 
philosophy, deepens it, taking as a point of support the concept of freedom of the will as the foundation of moral law.

\section{Elementary Philosophy of Reinhold and the Primacy of Practical Philosophy}

One cannot understand the scope of the central problem and the hypothesis that guide him without showing, albeit very quickly, some moments of Reinhold's philosophical trajectory. The real beginning of the development of his foundational theory takes place in Essay, a text already mentioned, with two related objectives. The most immediate is, with the theory of representation, to ground philosophically the unity between the theoretical and practical domains of reason starting from a single and first principle ${ }^{4}$. This goal, in turn, serves a broader one, that of constituting a philosophy as an apodictic science that could thus put an end to the philosophical quarrels of its time. The principle of representation would be in these terms the single root of the three superior faculties of the mind: sensitivity, understanding and reason. The philosophical gain intended by Reinhold, with the single principle of representation, would be above all systematic. From the same principle, representation in general, it would be possible to enunciate the properties of all species of representation, since the concept of representation would encompass "what has in common the sensation, the thought, the intuition, the concept and the idea" (Reinhold 2013, § X) ${ }^{5}$. Naturally, it is already possible to realize that Reinhold starts from Kant's Critique of pure reason, although that, according to him, could only be the starting point for solving philosophical problems, but not the answer itself.

Reinhold's criticism to Kant leads him to a philosophical project that aims to be more radical than the Kantian. It would not be up to Elementary philosophy ${ }^{6}$, as Kant would have done, to restrict its scope to the problem of metaphysics as a science of intelligible objects, nor to take formal logic as the foundation of the investigation. In other words, true Elementary philosophy cannot and absolutely must not be founded on formal logic, on the contrary, logic must be founded on it. Not being able to establish itself in any knowledge given beforehand, not even on general logic, Reinhold has to seek the most fundamental ground elsewhere, namely, in theory of representation, the general principle of all particular species

\footnotetext{
${ }^{4}$ This first principle that is neither analyzable nor determinable is the fact of consciousness or faculty of representation in general.

${ }^{5}$ My translation.

${ }^{6}$ Reinhold puts the fact and not the definition at the base of his philosophy, something hitherto unheard of in the foundation of any philosophical system (even for critical philosophy), where the only principle determined by himself is given by the very formulation of this fact and, by through it, it is also given "the first and highest definition from where must start philosophy in general and, in particular, elementary philosophy as the science of the faculty of representation" (Reinhold, 2011, p. 94). Reinhold thus wants to avoid the circularity that exists in every definition. Trying to give a real definition of simple representation is to re-establish a concept of representation, which would not itself again be a representation. In other words, the name Elementary philosophy comprises Reinhold's entire foundational project, which encompasses both practical (moral) and theoretical philosophy.
} 
of representation, which it relies on only in the fact of consciousness (Tatsache des Bewusstseins) ${ }^{7}$.

The justification for this is that the concept of representation, being immediately extracted from consciousness, is absolutely simple. As such, it cannot be analyzed in other elements that precede it, nor can it be explained by another concept or principle (otherwise there would be a vicious circle, which would prevent it from being the first). Hence it is also self-evident, a property which makes it entirely adequate to provide the ultimate foundation of all explanation. In these terms, mere representation constitutes the propaedeutic to found not a particular knowledge of objects, but the sciences of the faculty of knowing and desiring. For this reason, although it is also propaedeutic, Elementary philosophy of Reinhold does not have a restricted scope like Kantian propaedeutic, for it is propaedeutic not to metaphysics, but to all philosophy, both theoretical and practical: "the science of the faculty of representation cannot remove the characters from the concept of representation [only] from a part of philosophy" (Reinhold 2011b, p. 76), as the author of the Critiques wanted.

However, it is difficult to understand the primacy of practical reason that Reinhold confers to the Elementary philosophy, object of controversy among some of his readers. The difficulty is that Elementary philosophy turned more sharply to the theoretical domain of philosophy, without denying, however, the primacy of practice. This was already present in the first and third books of the Essay, whose theory of reason presents, in a quick but intense way, a theory of the faculty of desire $^{8}$. There, representation is seen unfolding in a direct relationship with freedom. Despite being asserted, the effective primacy of practical philosophy is not fully developed or consolidated, since Reinhold always emphasizes speculative reason. So much so that many interpreters see Reinhold's philosophy of this period as just a theoretical philosophy.

Notwithstanding, in my point of view the problem in this period of Reinhold's philosophy is neither in the scope of his work nor in the practical primacy he claims, but in the way to establish them. The method of deriving the fact of consciousness (Reinhold 2003, III, $\S)^{9}$, then proposed by Reinhold, became so

\footnotetext{
${ }^{7}$ Reinhold states in first book of the Essay that every concept of knowledge presupposes the concept of representation, since all that is knowable must be representable. In this way, only representation can say what is representable or not. That is why Reinhold starts from the theory of representation to build his philosophical project, because the concept of representation, being something that everyone agrees on, would reach universally accepted validity, although its concept is not the same for everyone because until now it had not been well investigated, not even by Kant. On the other hand, a definition of it would lead to the circularity, but this does not mean an obstacle to the configuration of a theory of the faculty of representation, because independently of an explanation, the mere representation remains possible, in which the attributes by which it is conceived can be specified. Without them, representation cannot be conceived. In this explanation of the concept of representation, a dissection or total exhaustion of the concept must appear, that is, everything that is representable in this concept must be given and everything that is representable while it is representable (see Lazzari 2004, p. 69).

${ }^{8}$ Fundamental lines of the theory of the faculty of desiring (Grundlinien der Theorie des Begehrungsvermögens) (in third book of the Essay, pp. 560f).

${ }^{9}$ In this chapter Reinhold says that there is no priority between consciousness in general and representation in general. But at the beginning of the third book of the Essay he states that one is
} 
enigmatic that it generated a fierce debate in its time, as well as the similar debate about the "fact of reason" in Kant's moral theory, which so much troubled the author of the Essay.

Probably, one of the difficulties arising from Elementary philosophy can be attributed to Reinhold's choice for a "shorter path" (kürzer Weg) than that explored by Kant in critical philosophy. In place of transcendental scheme, Reinhold elaborates degrees of spontaneity (or representation), having sensitivity as the first degree, where affection occurs; the third and highest is task of reason and consists in the production of the idea ${ }^{10}$. As in Kant, it is the understanding that make the mediation between sensibility and reason, providing, from concepts, the second degree of spontaneity. Reinhold makes the transition to the third degree of representation through an indirect judgment, or syllogism. Thus,

he shows that the categories determined a priori by the understanding, depending on the form to which they are related, are capable of completely opposite determinations: if related to the form of sensibility, insofar as they belong to the understanding as mere forms of judgment, they are neither conditioned nor unconditioned; as they are determined in the schema by time, they belong to the understanding and are conditioned. But when they are finally determined a priori in the form of the syllogism, they belong to reason and are unconditioned. Thus, the representation of the unconditioned unit that is determined a priori in the form of the syllogism is idea in the strictest sense and, in fact, the highest and most general idea, and the attributes of the object of this idea determined in nature in reason, or pure unconditioned unity represented are universality, infinity, comprehensiveness and absolute necessity (Reinhold 2013, p. 511) ${ }^{11}$.

In this process, Reinhold reverses the Kantian transcendental deduction, making it progress linearly from the presupposed foundation, which is an immediate principle ${ }^{12}$, to the other faculties, and places the idea of freedom or absolute cause at the top of the theory of degrees of spontaneity. Thus, on this third

different from the other, since consciousness in general is broader, as it comprises representation, where subject and object are distinct from it.

${ }^{10}$ See Onnasch (2005). In this text Onnash says that although Kant has made an important innovation with the close connection between intuition and category, because without intuition, the category is mere "form of thought" ( $\mathrm{KrV}$ B 309), Reinhold is the first to try to prove the completeness of the tables of judgments and categories. His text is important to understand the action of judgment in the passage from one degree of representation to another, since in it two actions always occur: through one, the objective unity is produced from intuition and, through the other, it is again connected to intuition.

${ }^{11}$ My translation.

${ }^{12}$ In distinguishing Kant from Leibniz, Reinhold shows that is very aware of the importance of the notion of synthetic unification of representations, a notion that, notably, plays a key role in deduction. Therefore, Reinhold intends to deduce, "from the faculty of representation in general, a priori, all the formal components of representation, without never noticing the essentially derivative and particular character, contingent on the human faculty of representation" (Chenet 1989, p. 39). This means that Reinhold, although in favor of the synthetic unity of representations, does not approve of the Kantian deduction of categories, because it proves synthetic knowledge $a$ priori according to the principle of possibility of experience, which for Reinhold is contingent. His transcendental deduction starts from the fact of consciousness, an autonomous and self-evident proposition, and not from the possibility of experience. 
level, spontaneity would incorporate an absolute self-activity, and the unity produced by it would be absolute. According to Reinhold, the action of reason is the only action of the representing subject that can be thought of as both uncoerced and unrelated to anything, that is, as free, since it is not linked to any strange form in the production of the idea, and so it is also the only passage that leads to the realm of practice. In this sense, Reinhold claims that the unconditioned unity is, then, an indirect attribute of knowable objects, of phenomena and of experience; "an attribute that refers to the objects through the concepts that occur in themselves and belong to their form, concepts that, through reason, receive an unity that the understanding connected with intuitions cannot give them: the unity of reason" (Reinhold 2013, pp. 514-515).

Indeed, in this third degree, the subject of the faculty of representation is immediately representable only by reason, through an idea, not by understanding, and it must be conceived "as a free cause insofar as it is conceived as an absolute cause, and it must be conceived as an absolute cause insofar as it is the subject of reason" (Reinhold 2013, p. 537). Absolute cause does not need the connection between objective matter and the schema to acquire objective reality, but only the immediate relationship with the representing subject in an absolutely formal thirddegree spontaneity.

This is the place where Reinhold finds himself at the end of Essay, believing has escaped of the difficulties that the Kantian concept of freedom presented. The author criticizes the Kantian postulates; he does not accept the causal series that goes to infinity nor the sovereign good as well as a supersensible foundation that constitutes the morality. But it is from here that the difficulty of the Reinholdian enterprise can be seen more clearly.

\section{The Difficulty of Elementary Philosophy: The Primacy of Practical Reason and the Problem of Method}

The main difficulty of Elementary philosophy is not in the unilaterality of the analysis of theoretical knowledge, but in the way of demonstrating the primacy of practice. Indeed, the difficulty arises when considering what is at stake in the third level of spontaneity. The ideas of absolute cause, absolute subject and absolute community (this is an attribute of the absolute subject) - three activities of the rational unit exposed by Reinhold, do not hold themselves on the theory of the faculty of reason contained in Essay. There were many objections, such as that in the third level, Reinhold cannot meet the requirement that in every representation there has to be form and matter, because there is only the form in these level (Lazzari 2004, pp. 161-162).

There is, however, another objection that will be more devastating, that which concerns to the justification of a freedom that provides the basis for pure and empirical will alike. In these terms, the problem reaches the core of Reinhold's proposal to provide a single philosophical foundation for the two realms of reason (theoretical and practical). The difficulty that the objection points out is evident in the theory of the faculty of will in the face of Reinhold's attempts to deduce a pure 
and an empirical will from the same ground. In this text, pure will in general is called the faculty that consists of self-determination for an action and, from it, actions of reason are derived according to its objective, be it empirical (when the action of reason is subordinated as means of satisfying the drive towards happiness) or moral (mode of action of reason is according to no other law than that which it gives itself when it realizes the mere form of reason, a form determined according to its possibility, through its self-activity).

The problem that then presents itself in this attempt is that the will is considered equally free in all its statements, but it maintains, however, a difference in the degree of activity of spontaneity, or in the mode of action of a free being. The will in general is free, but it can act comparatively or absolutely free, that is, if the action of the human will submits itself to the laws of the interested drive and is compelled by an affection foreign to it, it acts only in a comparatively freeway, but insofar as it follows the law of disinterested drive, which receives its sanction as effective law only through the mere self-activity of practical reason, by which it submits itself, it acts and is absolutely free.

In Reinhold's text the point at which he relativizes the will is obscure. It is strange to accept that the same will is absolute and also comparatively free. In fact, the author seeks to dwell on both, and this is also what makes his theory embarrassing. On the one hand, the freedom of the representing subject must be understood as freedom of choice to be able to decide for or against the moral law, because that is the only way to prevent moral actions from being random, which would lead to suppression (Aufhebung) of all morality. Furthermore, such freedom of choice must also be compatible with the will in general, which must be in the decision for or against the moral law. On the other hand, only the decision in favor of the moral law can be understood as a self-determination of reason, which then faces a power to determine itself (Sich-Bestimmen-Lassen) through the objects of sensibility (Reinhold 2013, p. 90).

Everything indicates that the problem arises due to the Kantian identification of freedom and autonomy, regardless of whether it is possible to reconstruct the Kantian model of determination of will by means of the Reinholdian philosophy. The Essay's statements are a theorem taken by Reinhold from the Kantian equation of freedom and autonomy in the Groundwork of the metaphysic of morals $^{13}$ and in Critique of practical reason. That is, freedom and the legislation proper to a pure practical reason are the same thing, since the empirical (or $a$ posteriori) will is never self-determination and free like the pure will (Lazzari 2004, p. 146). In second section of the Grundwork, Kant says that the will is a faculty of choosing only what reason, regardless of inclination, recognizes as practically necessary, that is, as good ${ }^{14}$.

\footnotetext{
${ }^{13}$ See mainly Kant's (1968) argument at the beginning of the third part of the Groundwork of the metaphysic of morals (Grundlegung zur Metaphysik der Sitten). Henceforth Grundwork.

${ }^{14}$ Grundwork, 36. Everything in nature acts according to laws. Only a rational being has the power to act according to the representation of laws, that is, according to principles, or a will. Since reason is required to derive actions from laws, will is nothing more than practical reason. If reason determines the will infallibly, then the actions of such a being, which are known to be objectively necessary, are also subjectively necessary, that is, the will is a faculty of choosing only what reason, regardless of inclination, recognizes as practically necessary, that is, as good.
} 
However, the maintenance of this identity seems to be understandable in Kantianism, because only this way can one hope to deduce, from the concept of freedom of will, the concept of a moral law that is valid for all actions.

The texts show that this is also the expectation of Reinhold, who assumes, from this foundation of Kant, not only the thought of a freedom of will common to the moral and non-moral actions, but also that of a freedom that is identical to autonomy. It is quite likely that the author's difficulties in deducing general and empirical will from the same foundation are a consequence of this grounding in Kant's texts. Once it is assumed that reason only as pure, in a pure will, is practical, or rather, that practical reason and a pure will are identical, then only pure (and not empirical) will is the possible expression of will. This means, on the one hand, the lack of a conceptualization to describe the will as such distinct from a pure will. On the other hand, this brings as a consequence the transformation of the non-pure will into desire. After all, since the a priori determination of the faculty of desire leads only by reason to a pure will, the activity of reason in empirical will can be only a posteriori determination of the faculty of desire. Although, such a determination accomplishes absolutely no will, but only the nature of a desire ${ }^{15}$.

Since Reinhold did not present explicit and unequivocally determinations of his absolutely free cause and of a will that expresses itself either as pure or as empirical, it is probably because he does not simply want the deduction of an absolutely free idea of cause, he wants it in the intended framework of the theory of the faculty of representation. This is precisely the possibility: either the idea of an absolutely free cause that fits in this framework, or that it expresses itself with the form and matter conceptualization of the theory of the faculty of representation, which, for Reinhold, constitutes the deduction of this idea and at the same time the justification of its logical possibility. However, by this framework, the wished deduction is very far from being achieved, on the contrary, it prevents its definitive realization to the extent that the Reinhold's representation "never effectuate itself only by the self-activity of the representing subject but, for this, it is also always necessary a given matter, to which this self-activity is connected and which can only be treated according to certain rules originally laid down" (Lazzari 2004, p. $153)^{16}$.

However, it should be noted that Reinhold realizes the central problem contained in Essay only after reading Carl Schmid's criticism presented in

\footnotetext{
${ }^{15}$ For Reinhold, unlike Kant or Leibniz, desire is not will. Desire is just the demand of the interested drive. Will is freedom, the faculty of the person to determine himself for the effective satisfaction or dissatisfaction of a demand of the interested or disinterested drive. A will that has autonomy of free will (not the free will that Kant reserves exclusively the power to choose the law according to the maximum), which has the power to act for or against moral law.

${ }^{16} \mathrm{My}$ translation. In every representation there must be form and matter, hence if Reinhold aspires an absolutely free cause, or a free activity of the representing subject within the framework of the theory of representation, the activity of this subject will never be independent of the form and matter relation. That is, the action of a free representing subject would escape the requirement of not being coerced and not linked to anything foreign to it, for there will always be a matter given from outside. In other words: within the framework of the theory of representation, a free and absolute action is impossible, because either it falls into formalism (which would mischaracterize the original rules that in every representation there must be form and matter), or the action would be linked to a matter, which prevents it from being absolute.
} 
paragraph LIX (59) of his work Empirical psychology, edited in Jena in 1791. According to Schmid (1791), "the internal foundation of determining an activity, whereby only one representation in general is effected, once represented, cannot be sought again and found in a representation, therefore, nor also in any purpose that represent itself" ${ }^{\prime 17}$.

This means that the original creation of representations, the activity in which a representation takes effect, is not correctly defined in its determination if one uses an already existing representation, because that would end up in a regress. We are dealing here, then, with a definition of the activity in which only one representation in general is effective, the true representation in the strict sense. Among the faculties the author rigorously differentiates those in which representations are possible (the faculty of representation with its representing force) and those that are possible only through representation (the faculty of the mind with its capacity for feeling, and the faculty of desire with your capacity to desire). Therefore, the faculty of representation is not, according to Schmid, an absolutely fundamental faculty in the sense that the other faculties were given by it or were already contained in it (Schmid 1791, p. 173).

Approaching his explanation succinctly, Schmid meant by this that the division of the powers of the mind becomes wavering when considering all efforts, every drive or instinct for the faculty of desire or even for will. Thus, it is assumed that the mind (Gemüt) acts blindly in the representation of certain objects (of the senses, understanding or reason) before a conscious effort originates. "Hence, necessarily, there have to be actions of the mind before desire and will, but they have been confused with expressions of will, thus impairing the accuracy of the method". He states that when Reinhold admits that drives do not all belong to the faculty of desire, these definitions must now appear to him as insufficient, for with this the being determined by the drive is also realized in other faculties, so that this characteristic mark no longer is enough to differentiate the faculty of desire from other faculties ${ }^{18}$.

Schmid does not explicitly mention Reinhold's name in his review, but Reinhold recognizes himself in it. In his letter to Baggesen in early 1792, Reinhold admits the fact that not all drives can be thought of as forms of desire. He ends up acknowledging, by Schmid's objection, that the being determined by the drive to create a representation cannot be understood as desire, because then the necessary presupposition of the representation would be the already constituted desire, not

\footnotetext{
${ }^{17}$ My translation.

${ }^{18}$ In Essay, the drive (Trieb) of the representing subject is the link between the representing force and the faculty of representation. The first is the real foundation of representation, the second is the foundation of its mere possibility. The relationship between them, present in every representing subject, determines the effectiveness of the representation, because together they provide spontaneity and receptivity, that is, the form and the matter of representation. Therefore, "to be determined by the drive for the production of a representation means desire, and the faculty to be determined by the drive, in a broader sense, means the faculty of desire (Essay, 560-1). The faculty of desire is determined by the drive for real sensations, for sensation is the representation that is related to the subject as simple modifications of the mind that arise from the way of being affected. These modifications refer either to the form of receptivity or to the form of spontaneity determined in the faculty, and from them it is defined whether the drive is sensitive or intellectual.
} 
the drive. He realizes that the more original the faculty of desire and representation tend to be, the more difficult will be to classify them together under a superior and comprehensive faculty of representation, falling apart the attempt to deduce a free and absolute cause.

There were several objections to the theory of the faculty of representation contained in Essay, but the one that most touched the author, causing him to decline some concepts, was Schmid's criticism against the determination of drive and desire in the theory of the faculty of desire. Reinhold realizes that in this theory, the power which is attributed to the reason, mainly in the deduction of absolute freedom, cannot be provided by one and the same faculty. As a result, he changes his interest to a uniform rational concept to describe the actual creation of the idea as creating a representation of reason in the mind. On the one hand, the reason to establish rules and limits, on the other hand, the will, as autonomous, no longer allows the faculty of desiring to be derived from reason.

\section{The New Method of Proof of Moral Philosophy: The Deepening of Philosophy of Reinhold}

We have seen that Reinhold's answer to the question in Essay is unsatisfactory: in what does consist the possibility of freedom? From the texts of 1792, mainly in Letters on Kantian philosophy (Briefe II), the author turns to the difficulty that prevented him from satisfactorily carrying out his fundamental task within the framework of the theory of the faculty of representation.

This text shows an evolution in Reinhold's argument when dealing with the problems of the Kantian system. His interest is no longer only in first Critique, but also in Critique of practical reason, and he is concerned with misunderstandings not only of critical philosophy but also with complex problems involving morality, natural right and the freedom of the will. The approach to conceptual determination in the theoretical and practical ambit is transformed. There is an emphasis on the idea of law and rules that indicate the priority reference of the interested drive and its satisfaction, as well as the thought of a complete subject that includes the representing subject. Reinhold (2004) expresses the differences took place in the conception of will and practical reason, as well as the interest in the theoretical recovery of the concept of person (Person):

Will means the person's faculty to determine himself for the satisfaction or not of a demand of the interested drive. I say the person's faculty and not reason. This is the faculty to give prescriptions (to produce rules). It belongs to the will only insofar as the person can determine himself by means of a prescription that he himself gives for the satisfaction or not of the interested drive. Only it is not the will itself. An action of the will is also not, in any way, every prescription that is given and carried out by the rational subject, but only the one through which this subject is determined for the satisfaction or not of a demand of the interested drive. Consequently, we made mistakes about the concept of will when we look for it both in the mere faculty of reason and in the mere interested drives (Reinhold 2004, pp. 111-113). 
Now the part of activity that formerly belonged to reason is attributed to the will, which can no longer be identical with the freedom of practical reason, since it comes into being as a characteristic of the faculty that the will accomplishes (Bondeli 2008, pp. LXX-LXXI) $^{19}$.

Mainly in the sixth, seventh and eighth letters, after a renewed analysis of Kant's moral texts, the concept of freedom of the will appears as the foundation of practical elementary philosophy. The free will is no longer found as a moment of the moral law, but the moral law as a moment of the self-activity of the free will, which is capable of deciding for or against the law. The seventh letter shows that the concept of will must determine the relationship between the interested and the disinterested drive. It becomes the middle term, or articulation, between the two drives and has the same position as the concept of representation in the structure of consciousness, which also mediates the relationship and difference between the representing subject and the represented object. Although, the will has a different function from representation, its work consists not only in differentiating itself for or against each individual drive, but also between the two drives: the interested and the disinterested. The will does not correspond to the relating and differentiating from the possible representation, but to the representing subject and its action of relating and differentiating (Reinhold 2008, p. 207). In other words, the drive is no longer the foundation of the will as it was in the Essay, but the will decides on it.

Also, the need to adapt common understanding to the appreciation of philosophical reason no longer exists in the Letters (Briefe II). Now it is this that must adapt to the infallible sentence of common understanding, since the conviction of this is the justification of the concept of freedom of will and, in this conviction, there is no contradiction that can discredit it before the judgment of philosophical reason. Both are precisely linked to the same fundamental faculties of the human spirit,

and they announce themselves in common understanding by irresistible and infallible feelings (Gefühle) and, through them, provoke convictions on which the philosophical reason, which seeks the foundations of these feelings, must remain at odds with itself as long as it fails to establish certain and distinct concepts of the fundamental faculties. The common understanding conceives the soul as an appearance of the inner sense, which it knows through the inner feeling as facts of consciousness and from whose reality it infers its possibility. For him, freedom is real according to the testimony of self-awareness and, consequently, also possible (Reinhold 2008, p. 207).

Therefore, for common understanding according to the testimony of selfconsciousness, freedom "is also possible, effective and consequential" (Reinhold 2008, p. 309). But the philosophical reason, although it conceives the soul as the bearer subject of the causes of the appearances of the internal sense, may hence not be content with knowing these appearances through mere feelings and, therefore, pursues searching for concepts of the foundations of these feelings. Unlike the sane understanding, which infers of reality the possibility of facts of consciousness,

\footnotetext{
${ }^{19}$ Reinhold refers here to the formula of consciousness expressed in Essay: "In consciousness, representation is differentiated from subject and object, but related to both by the subject".
} 
philosophical reason only accepts reality if it is convinced of the possibility and it will only be satisfied with itself about this reality, when it can answer the question: "what does it consist of the possibility of freedom? In other words, when it has reached a definite and distinct concept of freedom as a faculty of the mind" (Reinhold 2008, p. 208).

Nevertheless, philosophical reason, precisely because it cannot provide any justification for the possibility of freedom, must be satisfied with the results of the common and sane understanding in relation to reality and the possibility of freedom of will, because the starting point of such a "justification" would be the self-consciousness of freedom itself, assumed as infallible and absolutely certain, which, by itself, excludes the possibility of a refutation of the convictions of sane and common understanding by philosophical reason. This means that the philosophical reason, through its concepts, brings only the insight (Einsicht) of the sane understanding to the concepts and, together, it brings the justification of freedom. Thus, by assuming the freedom of the will as a fact of consciousness, the convictions of the common and sane understanding never contradict the philosophical reason according to itself, and the freedom of the will, rooted in the faculty of the mind, or soul, becomes both a feeling and a determinate and distinct concept.

\section{Conclusion}

What Reinhold has in mind here is to reject Kant's statement in the preface of Critique of practical reason according to which the reality of freedom is proved through an apodictic law of reason, that is, it reveals itself through the moral law (Kant 2003, A 4). His annoyance is because nowhere does Kant refer to a condition that should be fulfilled along with the conscience of the moral law for the adoption of the reality of the freedom of the will. His remarks greatly reinforce the interpretation that sees in the conscience of the moral law the only sufficient condition of our conscience of freedom. This rejection refers to the Kantian thesis of the fact of reason. The moral law, says Reinhold, is not given to us in an immediate consciousness as a fact of reason, because we are directly conscious only of two drives, one interested and another disinterested, and a faculty to decide for or against one or the other. To us is allowed to know only our freedom of will, which is only originally given to us as a disinterested drive, as a manifestation of practical reason. In this sense, he directly says that "the reality of freedom depends on the awareness of the demand of both the interested and the disinterested drive, and not on the awareness of the interested drive and practical reason" (Reinhold 2008, p. 256). Therefore, the concept of freedom does not maintain its reality just by the awareness of the moral law, as Kant wanted, since it is not quite the awareness of the moral law as such that originally accompanies our selfconsciousness of freedom, but only the conscience of the disinterested drive (although not independent of the conscience of the interested one). In other words, Reinhold does not understand will in its essence as the causality of reason. Freedom is free, but reason no. Only awareness of the demand of the two drives forms the sufficient condition for the freedom of the will. And only self- 
consciousness of the freedom of the will makes it possible to understand the disinterested drive or our moral feeling as an expression of practical reason. Therefore, Reinhold assures, moral action cannot be autonomous in the Kantian sense, in which the thought of legislation itself, according to which the instance that establishes the law is the same that receives and fulfills it, and the thought of a direct determination of the will for the moral law, two central marks of the autonomous will, leave pure practical reason only as a possible instance of action, but from which a decision against the moral law is not expected.

\section{References}

Bondeli M (2008) Einleitung in die Briefe über die kantische Philosophie. (Introduction in letters on Kantian philosophy). Basel: Schwabe Verlag.

Chenet FX (1989) Philosophie Elementary. (Elementary philosophy). Paris: VRIN.

Kant I (1968) Grundlegung zur Metaphysik der Sitten. (Foundation of the metaphysics of morals). Hrsg. von Wilhelm Weischedel, Werkausgabe, Band VII. Frankfurt/M: Suhrkamp Taschenbuch, Wissenschaft 56.

Kant I (2003) Kritik der praktischen Vernunft. (Critique of practical reason). Hrsg. von Horst D. Brandt und Heiner F. Klemme. Mit einer Einleitung, Sachanmerkungen und einer Bibliographie von Heiner F. Klemme. Hamburg: Felix Meiner.

Lazzari A (2004) Das Eine, was der Menschheit Noth ist. (The one thing that mankind needs). Luzern - Neapel: Frommann- Holzboog.

Onnasch EO (2005) Vorüberlegungen zur Herleitung der Urteilsformen und Kategorien in Reinholds Theorie des Vorstellungsvermögens. (Preliminary considerations for the derivation of the forms of judgment and categories in Reinhold's theory of faculty of representation). In MM Olivette (ed.), Archivio di Filosofia, LXXIII, n. 1-3. PisaRoma: Istituti Editoriali e Poligrafici Internazionali (MMVI).

Reinhold KL (2003) Beiträge zur Berichtigung bisheringer Missverständinisse der Philosophen. (Contributions to the correction of previous misunderstandings of the philosophers). Band I. Hrausgegeben von Faustino Fabbianelli. Hamburg: Felix Meiner.

Reinhold KL (2004) Beiträge zur Berichtigung bisheringer Missverständinisse der Philosophen. (Contributions to the correction of previous misunderstandings of the philosophers). Band II. Hrausgegeben von Faustino Fabbianelli. Hamburg: Felix Meiner.

Reinhold KL (2008) Briefe über die kantische Philosophie. (Letters on Kantian philosophy). Gesammelte Schriften. Kommentierte Ausgabe Kommentierte. Bände 2/2. Herausgebenen von Marin Bondeli. Basel: Schwabe Verlag.

Reinhold KL (2011) Über das Fundament des philosophischen Wissens. (On the foundation of philosophical knowledge). Gesammelte Schriften. Kommentierte Ausgabe. Band 4. Herausgebenen von Martin Bondeli. Basel: Schwabe Verlag.

Reinhold KL (2013) Versuch einer neuen Theorie des menschlichen Vorstellungsvermögens. (Essay on a new theory of the human faculty of representation). Gesammelte Schriften. Kommentierte Ausgabe. Band I. Herausgebenen von Martin Bondeli. Basel: Schwabe Verlag.

Schmid CCE (1791) Empirische Psychologie. (Empirical psychology). Jena: Cröker. 